\title{
Multiple thrombosis with native coronary involvement secondary to heparin-induced thrombocytopenia
}

\section{Trombosis múltiple con afectación coronaria nativa secundaria a trombocitopenia inducida por heparina}

\author{
Francisco de-la-Cuerda ${ }^{1}$, Pablo Díez-Villanueva ${ }^{1 *}$, Jorge Salamanca ${ }^{1}$, Natalia Acedo-Domínguez ${ }^{2}$, \\ Esther González ${ }^{1}$, and Fernando Alfonso ${ }^{1}$ \\ ${ }^{1}$ Department of Cardiology; ${ }^{2}$ Department of Hematology, Hospital Universitario de la Princesa, Madrid, Spain
}

\begin{abstract}
Heparin-induced thrombocytopenia (HIT) is a rare complication of anticoagulant therapy with heparin, secondary to the formation of anti-platelet factor 4/heparin complex (PF4/heparin) antibodies, which leads to the development of paradoxical thrombotic phenomena $^{1,2}$. The diagnosis of this entity is based on the demonstration of anti-PF4/heparin IgG antibodies in a clinical context of intermediate/high probability (4 or more points according to the $4 \mathrm{~T}$ scale). Its treatment should be instigated on clinical suspicion, with heparin immediate discontinuation and alternative anticoagulant drugs administration ${ }^{3,4}$. Although thromboses related to this phenomenon are more common in the venous area, arterial episodes, even in the coronary territory, have also been described ${ }^{5}$.
\end{abstract}

The case presented is about a 62-year-old male patient with previous history of dyslipidemia under treatment with atorvastatin, and an abdominal aortic aneurysm that had been recently treated with an aortic stent implantation $\left(25 \mathrm{~mm}^{\text {Endurant }}{ }^{\circledR}\right), 10$ days after hospital discharge, the patient requested home care for central chest intense oppressive pain. A 12-lead electrocardiogram was obtained, which showed ST segment elevation in inferior leads, and the patient was, therefore, transferred to the authors' center due to the suspicion of acute myocardial infarction (AMI). An urgent coronary angiography was performed, which revealed diffuse coronary ectasia with a large repletion defect in the anterior descending artery (ADA) at the proximal level, consistent with non-occlusive thrombosis, and total thrombotic occlusion (thrombolysis in myocardial infarction [TIMI] 0) in the middle right coronary artery (RCA), which was an aneurysmal vessel (Fig. $1 A$ and $B$ ). Percutaneous intervention in the RCA was ineffective, despite thromboaspiration and multiple balloon insufflations, thus the procedure concluded with a TIMI 2 final flow.

At the Acute Cardiac Care Unit, newly onset severe thrombocytopenia $(47,000$ platelets $/ \mu \mathrm{L})$ was confirmed. Due to the history of vascular intervention 10 days before (with previous platelet numbers at 138,000 platelet $/ \mu \mathrm{L}$ and subsequent count of 108,000 platelets/ $\mu \mathrm{L} 5$ days after the intervention) with exposure to unfractionated heparin at doses of $1 \mathrm{mg} / \mathrm{kg}$ of weight during the intervention ( $80 \mathrm{mg}$ ), and in the absence of other causes that justified such thrombocytopenia, the possibility of HIT was considered (high clinical risk with 6 points on the 4T scale). Treatment was started with low-dose fondaparinux (2.5 mg daily per subcutaneous route) on recommendation of the hematology department, and a blood sample was obtained for the
Correspondence:

*Pablo Diez-Villanueva

E-mail: pablo_diez_villanueva@ hotmail.com license (http://creativecommons.org/licenses/by-nc-nd/4.0/).

Date of reception: 05-06-2019

Date of acceptance: 18-02-2020 DOI: 10.24875/ACME.M20000138
Available online: 04-12-2020 Arch Cardiol Mex (Eng). 2020;90(3):329-331 www.archivoscardiologia.com
an open access article under the CC BY-NC-ND 


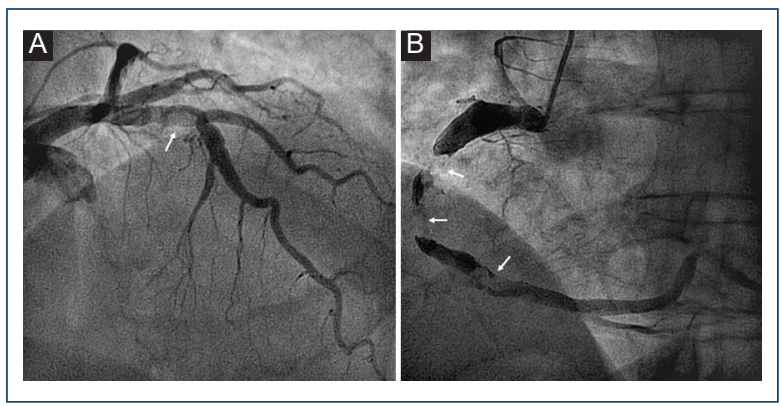

Figure 1. A: angiographic findings at the left coronary tree. B: right coronary artery. Arrows point at significant repletion defects, consistent with intracoronary thrombosis.

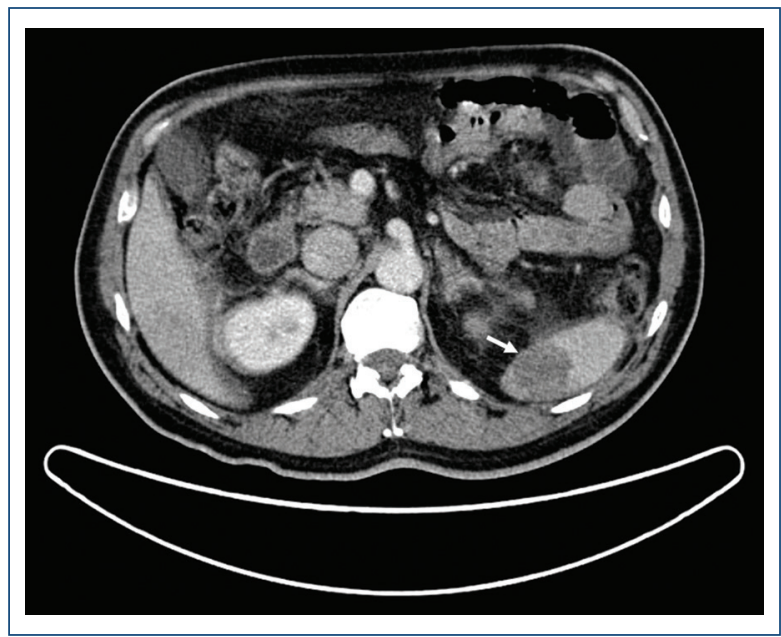

Figure 2. Intra-abdominal findings by computerized axial tomography, which show splenic infarction (arrow).

assessment for anti-PF4/heparin antibodies, the result of which was positive and confirmed the diagnosis.

Subsequently, the patient remained stable from the cardiologic point of view, without heart failure or arrhythmic episodes. Within the first $24 \mathrm{~h}$, the patient started with fever and abdominal pain at the level of the left flank, which prompted an abdominal imaging study by computed tomography, with a diagnosis of splenic infarction (Fig. 2), as well as slight thrombosis of the middle suprahepatic vein. In addition, perimeter increased together with local heat erythema. Lower limb Doppler ultrasound examination showed another thrombotic episode in a muscle perforating venous branch. Given the persistence of fever and Gram-positive blood isolation (Propionibacterium acnes), a
PET-CT scan was performed, which delineated a segmental perfusion defect in the right upper lobe consistent with pulmonary embolism, with intra-aortic prosthetic material infectious process being ruled out. Given these findings, the fondaparinux dose was increased to $7.5 \mathrm{mg} /$ day per subcutaneous route, without new recurrence of thromboembolic episodes, and progressive recovery of platelet counts to $159,000 / \mu \mathrm{L}$ (the lowest recorded number was 32,000 platelets $/ \mu \mathrm{L}$ ). Finally, the patient was discharged with acenocoumarol and anti-platelet aggregation treatment with acetylsalicylic acid (100 mg/day). Subsequent follow-up was indicated at the cardiology and hematology departments outpatient services, without of new ischemic episodes being reported and oral anticoagulation withdrawal after 12 months of treatment.

HIT is a recognized immune phenomenon with a variable incidence of $0.5-5 \%$ of exposed patients, depending on the heparin type and dose supplied ${ }^{3}$. Anti-PF4/heparin antibodies activate platelet aggregation and favor the development of venous and arterial thrombotic phenomena with platelet consumption and, ultimately, thrombocytopenia ${ }^{3}$. Coronary thrombotic events are very rare and, in particular few, cases have been described in patients with prior interventionism, both percutaneous and surgical ${ }^{5}$ (involvement of the native coronary tree is exceptional). Furthermore, the incidence of HIT in patients exposed to heparin in the context of a vascular operation is low, despite the development of antibodies in the post-operative period not being uncommon ${ }^{1,6}$. This case is interesting because of the compromise at various levels of the coronary tree with abundant thrombotic content in a patient with previous exposure to heparin and without known arteriosclerotic coronary disease, where the presence of coronary ectasia might favor in situ thrombosis. In addition, multiple thromboembolic phenomena at different areas were shown. In this patient, treatment with highdose subcutaneous fondaparinux stabilized the clinical situation, with platelet count recovery and no recurrences.

\section{Funding}

None.

\section{Conflicts of interest}

The authors declare that they have no conflicts of interest. 


\section{Ethical disclosures}

Protection of human and animal subjects. The authors declare that the procedures followed were in compliance with the regulations of the relevant ethics committee for responsible experimentation with human subjects and in accordance with the World Medical Association and the Declaration of Helsinki.

Confidentiality of data. The authors declare that they have followed the protocols of their work center on the publication of patient data.

Right to privacy and informed consent. The authors have obtained informed consent from the patients or subjects referred to in the article. This document is in the possession of the corresponding author.

\section{References}

1. Martel N, Lee J, Wells PS, Engström G. Risk for heparin-induced throm-bocytopenia with unfractionated and low-molecular-weight heparin throm-boprophylaxis: a meta-analysis. Blood 2005;106:27102715.

2. Gallagher MJ, Ajluni SC, Almani SL. Coronary artery stent thrombosis associated with heparin-induced thrombocytopenia: case report and review of the literature. J Interv Cardiol. 2005;18:131-137.

3. Cruz-González I, Sánchez-Ledesma M, Sánchez PL, Jang IK. Heparin-in-duced thrombocytopenia. Rev Esp Cardiol. 2007;60:1071-1082.

4. Cuker A, Arepally GM, Chong BH, Cines DB, Greinacher A, Gruel Y, et al. American Society of Hematology 2018 guidelines for management of venous thromboembolism: heparin-induced thrombocytopenia. Blood Adv. 2018;2:3360-3392.

5. Almeqdadi M, Aoun J, Carrozza J. Native coronary artery thrombosis in the setting of heparin-induced thrombocytopenia: a case report. Euro-pean Heart Journal-Case Reports 2018;2:1-5.

6. Lindhoff-Last E, Eichler P, Stein M, Plagemann J, Gerdsen F, Wag-ner R, et al. A prospective study on the incidence and clinical relevance of heparin-induced antibodies in patients after vascular surgery. Thromb Res. 2000; 97:387-393. 